\title{
A preliminary study of the low density particle boards quality using rice husks and oil palm empty fruit bunch with plastic waste adhesive
}

\author{
Muh. Yamin ${ }^{1}$, Rudito ${ }^{1}$, Andi Lisnawati ${ }^{1}$, and Mohammad Lutfi ${ }^{2, *}$ \\ ${ }^{1}$ State Agricultural Polytechnic of Samarinda, 75131, Indonesia \\ ${ }^{2}$ Department of Petroleum Engineering, STT MIGAS, Balikpapan, 76127, Indonesia
}

\begin{abstract}
The accumulation of rice husks (RH), oil palm empty fruit bunch (OPEFB), and plastic waste (PW) can reduce the fertility of the soil. The objective of this study was to compare the quality of the low density particle boards using that waste. Experimental design was used by testing the quality of particle boards with a substitution of $50 \%$ by weight of the total mixes for each waste (RH and OPEFB) and 50\% of PW with 3 replications. The results revealed that the quality of the low density particle boards based on water content, density, and modulus of rupture (MOR) tests meet the requirements of SNI 03-2105-2006, whereas the modulus of elasticity (MOE), thickness swelling, water absorption, and the tension perpendicular to surface tests do not comply to the requirements. This preliminary study revealed that the quality of particle boards using OPEFB was better than the particle boards using RH for building materials such as ceilings.
\end{abstract}

\section{Introduction}

An agricultural waste (AW) abundantly available in rice producing countries is rice husks [1]. The accumulation of rice husks $(\mathrm{RH})$ every year is one of the soil fertility problems that should be addressed due to the fact that it does not decompose at a fast rate [2].

Similar environmental problems also occur for oil palm empty fruit bunch (OPEFB) produced from the palm oil industry. In 1993, the area of palm plantation is approximately 14.7 million ha, in which east Kalimantan is the basis of oil palm plantation, which has potential waste of about 1.096.646 ton/ha [3]. Another dangerous waste for soil is plastic waste (PW). It will prevent the production of nutrients in the soil, so that the fertility of the soil is reduced and influences the agriculture sector [4].

One effort to reduce those wastes in the environment is the recycling process. The waste can be used to make a particle board. The research related to the particle boards have been conducted by many researchers [5-14].

Particle boards consist of three types based on the density, namely low density particle board $\left(<0.59 \mathrm{~g} / \mathrm{cm}^{3}\right)$, medium density $(0.59-0.8) \mathrm{g} / \mathrm{cm}^{3}$, and high density $\left(>0.8 \mathrm{~g} / \mathrm{cm}^{3}\right)$

* Corresponding author: lutfi_plhld@yahoo.co.id 
[15]. The research of the quality for the low density particle boards produced from AW and PW need to be concerned to minimize the production cost.

In this research, the utilization of RH and OPEFB with PW as adhesive for making the low density particle board is proposed. This is certainly very suitable in saving those materials and produce more products, it can be used for the allotment of products that do not require high density.

\section{Method}

This research was conducted by comparing the quality of the particle boards produced from RH and OPEFB using PW as adhesive obtained from plastic cups waste (polypropylene). The particle boards were produced in two different treatments with 3 replications for each treatment and the weight of each specimen was $162 \mathrm{~g}$. Design of mixes are as follows: $50 \%$ of RH: $50 \%$ of PW and 50\% of OPEFB: $50 \%$ of PW (by weight of total mixes).

The hot pressing was carried out in a hydraulic press, at a temperature of $175^{\circ} \mathrm{C}$ and pressure of $30 \mathrm{~kg} / \mathrm{cm}^{2}$ for a period of 7 minutes of total hot pressing. All particle boards were cooled and conditioned under the room condition for 4 days after hot pressing.

The physical and mechanical tests were conducted at a laboratory of forest products technology (Mulawarman University). The testing included several parameters such as water content, water absorption, thickness swelling, density, modulus of elasticity (MOE), and modulus of rupture (MOR) based on SNI 03-2105-2006 [16] and the tension perpendicular to the surface based on Food and Agricultural Organization (FAO) 1996 standard [17]. After curing, the cutting of particle boards was conducted for physical and mechanical tests. Fig. 1 shows the cutting pattern of specimens.

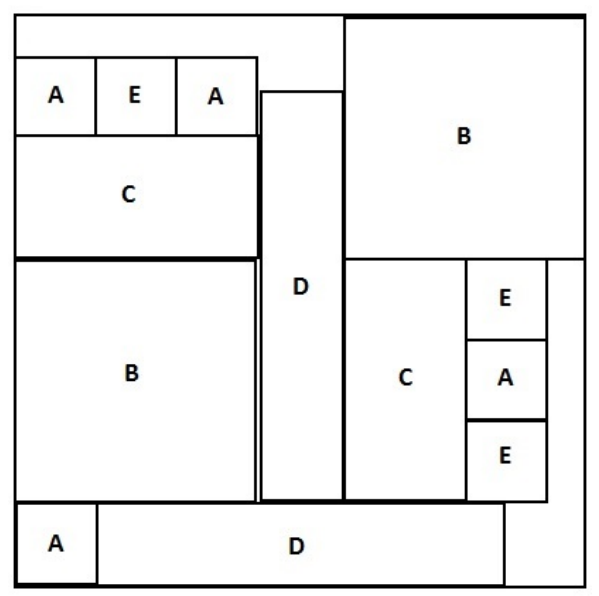

Fig. 1. The cutting pattern of specimens for physical and mechanical tests.

Where $\mathrm{A}$ is the specimen for water content and density tests $(5 \mathrm{~cm} \times 5 \mathrm{~cm}), \mathrm{B}$ is the specimen for water absorption and thickness swelling tests $(15 \mathrm{~cm} \times 15 \mathrm{~cm}), \mathrm{C}$ is the specimen for MOE and MOR $(15.2 \mathrm{~cm} \times 7.6 \mathrm{~cm})$ tests, D is the specimen for the tension parallel to the surface test $(25.4 \mathrm{~cm} \times 5.1 \mathrm{~cm})$, and $\mathrm{E}$ is the specimen for the tension perpendicular to the surface test $(5 \mathrm{~cm} \times 5 \mathrm{~cm})$. The thickness of the all the specimens is approximately $0.6 \mathrm{~cm}$. 


\section{Results and discussions}

\subsection{Water content}

The average values of water content of the particle boards produced from RH and OPEFB with PW as adhesive are $3.15 \%$ and $2.44 \%$ respectively. Fig. 2 shows that the results meet the requirement of [16], which requires the maximum value of water content to be $14 \%$. The low values are caused by the drying process of waste materials until they reach the constant weight and the hot pressing process was adequate to evaporate the water in the fiber of RH and OPEFB.

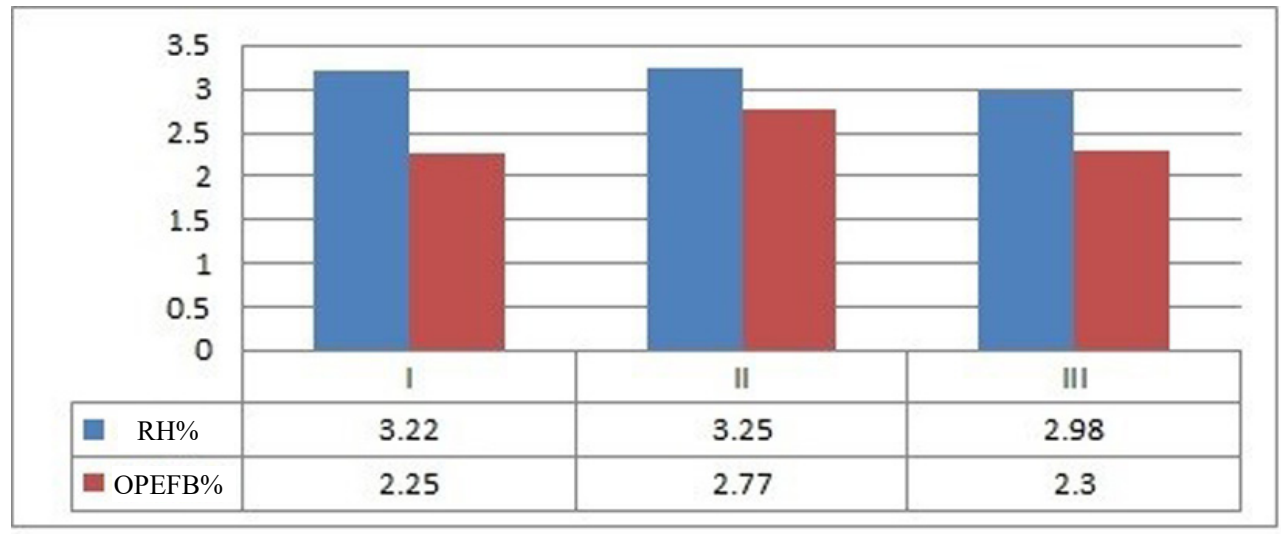

Fig. 2. Comparison of water content between RH and OPEFB.

\subsection{Water absorption}

A water absorption test was conducted to determine the amount of water absorbed by particle boards due to immersion in water. According to Fig. 3, water absorption based on [17] which requires water absorption to be $6 \%-40 \%$ are not fulfilled for either specimen. But in [16], water absorption criteria is not required. The result revealed that the average values of water absorption are $77.84 \%$ for $\mathrm{RH}$ and $82.38 \%$ for OPEFB respectively.

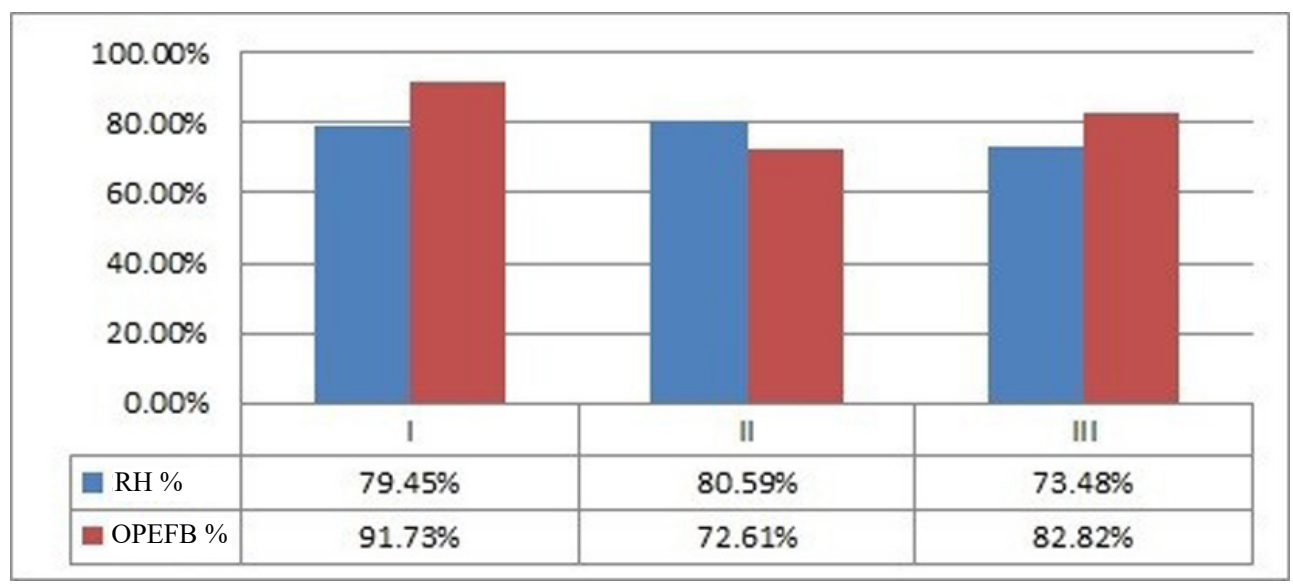

Fig. 3. Comparison of water absorption between RH and OPEFB. 


\subsection{Thickness swelling}

Thickness swelling test aims to study the change of thickness due to the amount of water that comes after immersion in a period of time. According to [16], the thickness change requires a maximum value of $12 \%$. Fig. 4 shows that the particle boards produced from RH meet the requirement based on three replications. Whereas for OPEFB, there is only one specimen that complies [16] and the other one does not fulfill the requirement.

The thickness swelling is affected by the duration of immersion in a period of time. The results show that the average values of thickness swelling for three replications produced from $\mathrm{RH}$ is $5.75 \%$ and $20.7 \%$ for OPEFB.

The distribution of PW for particle boards produced from $\mathrm{RH}$ is more uniform than OPEFB due to its shape, the porosity of particle boards produced from OPEFB is larger than RH. The true nature of OPEFB is that it absorbs much more water than RH, so that OPEFB is easier to inflate compared to RH during immersion process. However, the thickness swelling is not a requirement of [17] in particle board manufacture.

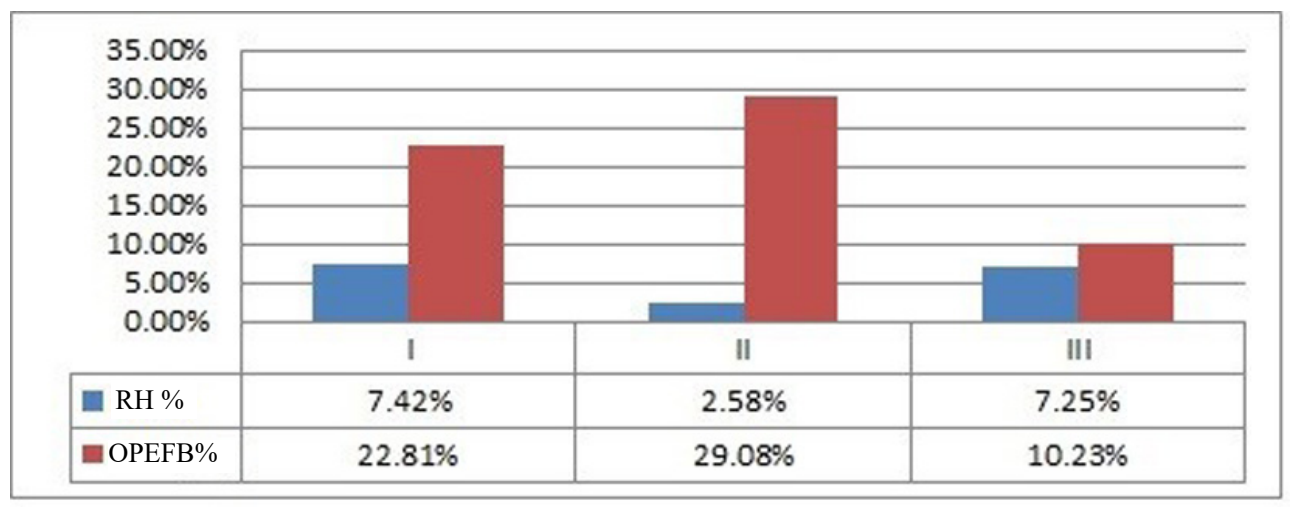

Fig. 4. Comparison of thickness swelling between RH and OPEFB.

\subsection{Density}

The density is influenced by the number of particles, the more the amount of RH and OPEFB are used, the higher the density of the specimens will be. The density based on [16] requires a value between $(0.40-0.90) \mathrm{g} / \mathrm{cm}^{3}$ and [17] $(0.42-0.80) \mathrm{g} / \mathrm{cm}^{3}$. Fig. 5 shows the values for both treatments ranging from $(0.52-0.59) \mathrm{g} / \mathrm{cm}^{3}$. The average values of density for $\mathrm{RH}$ is $0.57 \mathrm{~g} / \mathrm{cm}^{3}$ and for OPEFB is $0.55 \mathrm{~g} / \mathrm{cm}^{3}$. It shows that the density requirement complies for both standards. 


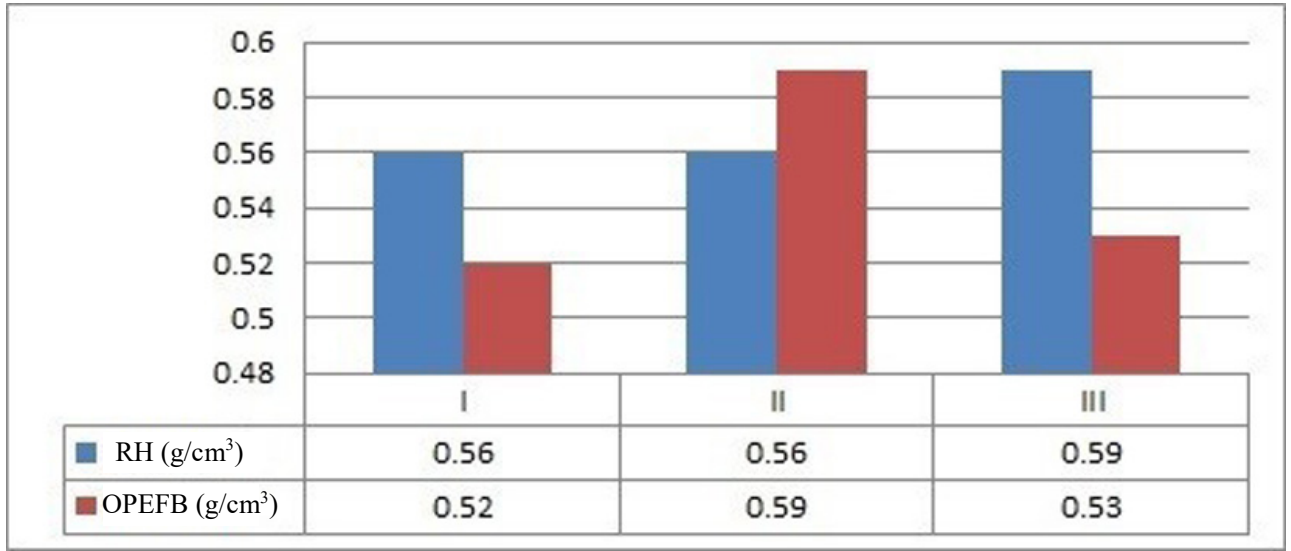

Fig. 5. Comparison of density between RH and OPEFB.

\subsection{Modulus of elasticity (MOE)}

Modulus of elasticity (MOE) test was conducted to study the capability of particle boards, which is given a load to reach its maximum limit and is then restored to its original state if the load is removed.

The minimum value of MOE is $20400 \mathrm{~kg} / \mathrm{cm}^{2}$ based on [16]. According to Fig. 6, the result revealed that both of the average values (RH has $2699 \mathrm{~kg} / \mathrm{cm}^{2}$ and OPEFB has 2778 $\mathrm{kg} / \mathrm{cm}^{2}$ ) do not meet the requirement.

A bad result of MOE can be caused by a small percentage and the lack of capability of the adhesive (PW) compared to the other adhesives, such as urea formaldehyde and phenol formaldehyde.

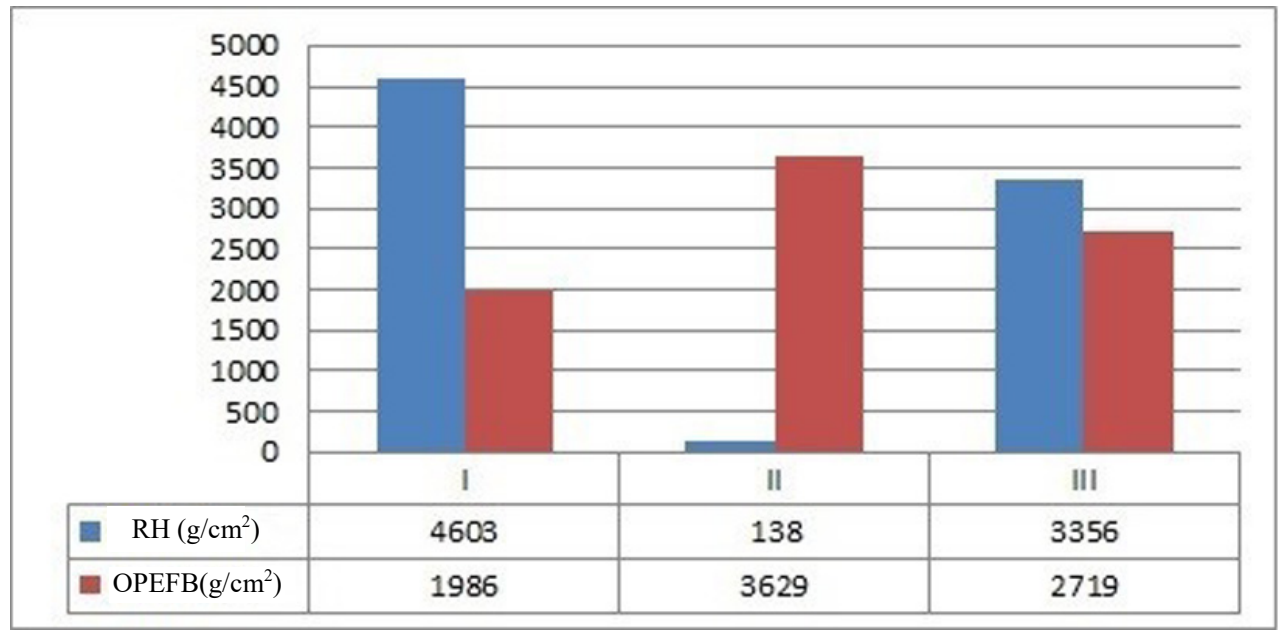

Fig. 6. Comparison of MOE between RH and OPEFB.

\subsection{Modulus of rupture (MOR)}

The MOR test is the other state of MOE test, where the particle board which is given a load to reach its maximum limit cannot restore to its original state, if the given load is over the 
limit, then particle board will break. This test is one of the most important requirements to determine the quality of particle boards for building materials.

The minimum value of MOR based on [16] is $82 \mathrm{~kg} / \mathrm{cm}^{2}$ and based on [17] are $108-$ $280 \mathrm{~kg} / \mathrm{cm}^{2}$. According to Fig. 7, both of the specimens comply for both standards with average values of $127 \mathrm{~kg} / \mathrm{cm}^{2}$ for $\mathrm{RH}$ and $157 \mathrm{~kg} / \mathrm{cm}^{2}$ for OPEFB.

Good results of MOR are caused by the rigidity of plastic as adhesive and the homogeneous distribution between AW and PW during the mixing process, this causes the strong bonds between RH and PW, as well as for OPEFB and PW due to the adhesion process.

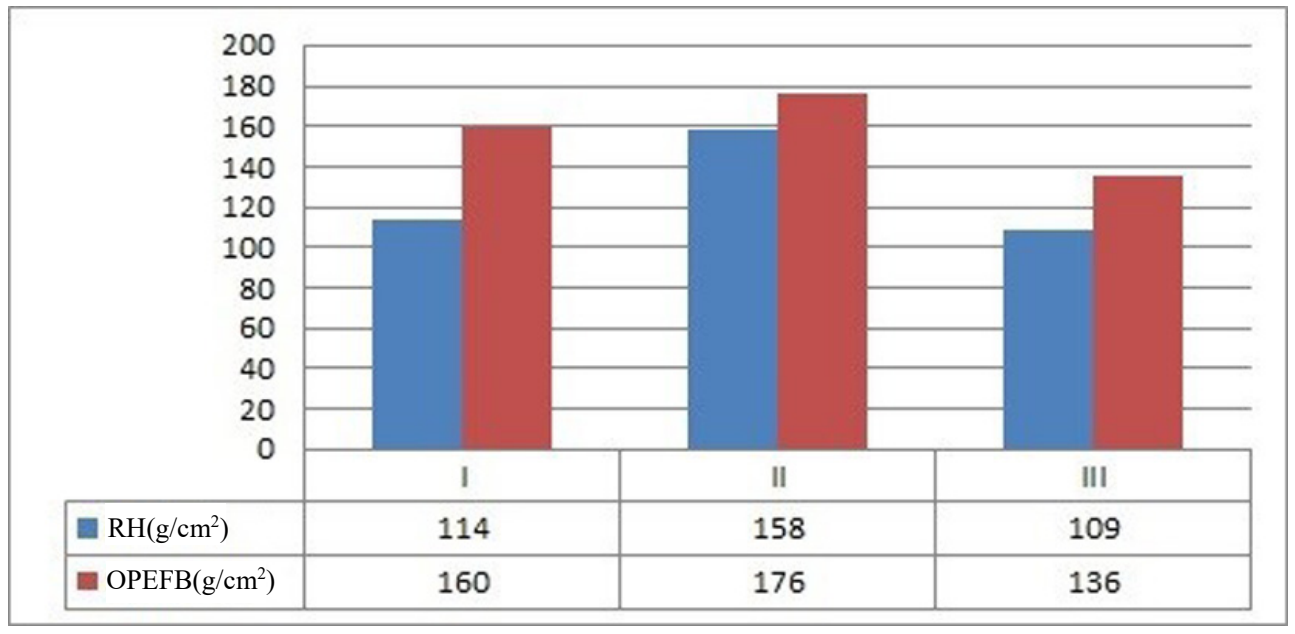

Fig. 7. Comparison of MOR between RH and OPEFB.

\subsection{The tension perpendicular to the surface}

The values of tension perpendicular to the surface is not included in the standard of [16]. Whereas the standard of [17] requires values of $85-210 \mathrm{~kg} / \mathrm{cm}^{2}$, Fig. 8 shows that the values of the whole treatment does not comply for both standards $\left(1.54 \mathrm{~kg} / \mathrm{cm}^{2}\right.$ for RH and 0.77 $\mathrm{kg} / \mathrm{cm}^{2}$ for OPEFB).

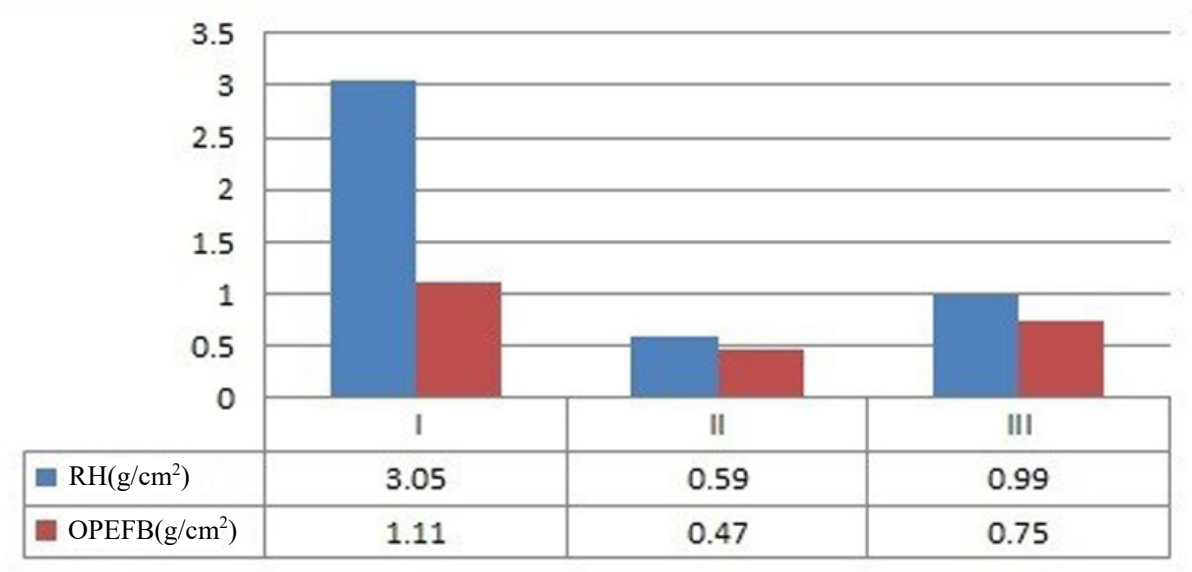

Fig. 8. Comparison of the tension perpendicular to surface between RH and OPEFB. 


\section{Conclusion}

The results revealed that the quality of the low-density particle boards based on water content, density, and modulus of rupture (MOR) meet the requirement of [15] and [16], whereas the modulus of elasticity (MOE), thickness swelling, water absorption, and the tension perpendicular to the surface do not comply to the requirement.

This preliminary study revealed that the quality of particle boards using OPEFB is better than using RH for building materials. The results of this research are expected to be used for ceiling based on MOR values, but further analysis needs to be performed to study the appropriate standard for ceilings.

This research is a preliminary study, therefore, further analysis is needed to be conducted by varying the composition of RH and OPEFB with many replications. A comparative study among the quality of particle boards produced from bagasse, $\mathrm{RH}$, and OPEFB with PW as adhesive will be the next research topic to be analyzed.

\section{References}

1. S. Thiyageshwari, P. Gayathri, R. Krishnamoorthy, R. Anandham, D. Paul. Exploration of rice husk compost as an alternate organic manure to enhance the productivity of blackgram in typic haplustalf and typic rhodustalf. International journal of environmental research and public health. 15, 2, p. 358, (2018).

2. G. A. Habeeb, M. M. Fayyadh. Rice husk ash concrete: The effect of RHA average particle size on mechanical properties and drying shrinkage. Australian Journal of basic and Applied Sciences. 3, 3, pp. 1616-1622, (2009).

3. Y. Fauzi, Y. E. Widiastuti, I. Stayawibawa, R. Hartono. Oil palm: Cultivation of waste utilization, analysis of business and marketing. Penebar Swadaya. Jakarta. (2004) (in Indonesian).

4. N. M. Dana Gopal, P. Phebe, E. V. Suresh Kumar, B. K. K. Vani. Impact of plastic leading environmental pollution. Journal of Chemical and Pharmaceutical Sciences. Special issue 3, pp. 96-99, (2014)

5. A. Olufemi. Sotannde, O. Abiodun. Oluwadare, Omaojor Ogedoh, F. Paul, Adeogun. Evaluation of cement-bonded particle board produced from afzelia africana wood residues. Journal of Engineering Science and Technology. 7, 6, pp. 732 - 743. School of Engineering, Taylor's University, (2012).

6. Y. Copur, C. Guler, M. Akgul, C. Tascioglu. Some chemical properties of hazelnut husk and its suitability for particleboard production. Build. Environ. 42, pp. 2568-2572, (2007).

7. R. Rodolfo de Melo, D. M. Stangerlin, R. R. C. Santana, T. D. Pedrosa. Physical and mechanical properties of particle board manufactured from wood, bamboo and rice husk. Materials research. 17, 3, pp. 682-686, (2014).

8. H. Kalaycioglu, G. Nemli. Producing composite particleboard from kenaf (Hibiscus cannabinus L.) stalks. Industrial Crops and Products. 24, pp. 177-180, (2006).

9. C. Lin, S. Hiziroglu, SM. Kan, HW. Lai. Manufacturing particleboard panels from betel palm (Areca catechu Linn.). Journal of materials processing technology. 197, pp. 445-448, (2008).

10. S. Mohamad Jani, K. Izran. Mechanical and physical properties of urea-formaldehyde bonded kenaf core particle boards. J. Trop. Agric. and Fd. Sc. 41, 2, pp. 341 - 347, (2013). 
11. K. Warmbier, A. Wilczynski, L. Danecki. Properties of one-layer experimental particleboards from willow (Salix viminalis) and industrial wood particles. Eur. J. Wood Prod. 71, pp. 25-28, (2013)

12. M. Dahmardeh Ghalehno, M. Madhoushi, T. Tabarsa, M. Nazerian. The manufacture of particleboards using mixture of reed (surface layer) and commercial species (middle layer). Eur. J. Wood Prod. 69, pp. 341-344, (2011)

13. M. Dahmardeh Ghalehno, M. Nazerian. Physical and mechanical properties of particleboard from roselle (Hibiscus sabdariffa) stalks and eucalyptus (Eucalyptus camaldulensis) wood particles. Wood Material Science and Engineering. 7, pp. 25-29, (2012)

14. M. Dahmardeh Ghalehno, M. Nazerian, A. Bayatkashkoli. Experimental particleboard from bagasse and industrial wood particles. Intl J Agri Crop Sci. 5, 15, pp. 1626-1631, (2013)

15. TM. Maloney. Modern particleboard and dry process fiberboard manufacturing. San Fransisco, Miller Freeman Inc. (1993).

16. National Standardization Agency of Indonesia. SNI 03-2105-2006. Particle Board. (2006) (in Indonesian).

17. FAO. Fiberboard and particle Board. (1997). Genewa. 